MIDAS

Museus e estudos interdisciplinares

$10 \mid 2019$

Varia

\title{
Emília Ferreira - Lisboa em Festa: A Exposição Retrospetiva de Arte Ornamental Portuguesa e Espanhola, 1882. Antecedentes de um Museu
}

Paulo Oliveira Ramos

\section{(2) OpenEdition \\ Journals}

Edição electrónica

URL: http://journals.openedition.org/midas/1550

DOI: $10.4000 /$ midas. 1550

ISSN: 2182-9543

Editora:

Alice Semedo, Paulo Simões Rodrigues, Pedro Casaleiro, Raquel Henriques da Silva, Ana Carvalho

Refêrencia eletrónica

Paulo Oliveira Ramos, « Emília Ferreira - Lisboa em Festa: A Exposição Retrospetiva de Arte Ornamental Portuguesa e Espanhola, 1882. Antecedentes de um Museu », MIDAS [Online], 10 | 2019, posto online no dia 31 maio 2019, consultado no dia 24 setembro 2020. URL : http://journals.openedition.org/midas/ 1550 ; DOI : https://doi.org/10.4000/midas. 1550

Este documento foi criado de forma automática no dia 24 setembro 2020.

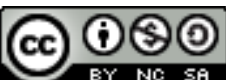

Midas is licensed under a Creative Commons Attribution-NonCommercial-ShareAlike 3.0 International License 


\title{
Emília Ferreira - Lisboa em Festa: A Exposição Retrospetiva de Arte Ornamental Portuguesa e Espanhola, 1882. Antecedentes de um Museu
}

\author{
Paulo Oliveira Ramos
}

\section{REFERÊNCIA}

Ferreira, Emília, 2017. Lisboa em Festa: A Exposição Retrospetiva de Arte Ornamental Portuguesa e Espanhola, 1882. Antecedentes de um Museu. Vol. 8. Coleção Estudos de Museus. Casal de Cambra: Caleidoscópio e Direção-Geral do Património Cultural. 319 páginas, ISBN: 978-989-658-499-4.

1 O livro dado à estampa em finais de 2017 corresponde à tese de doutoramento em História da Arte Contemporânea que a autora apresentou em 2010 à Universidade Nova de Lisboa sob orientação científica de Raquel Henriques da Silva.

2 O volume encontra-se organizado em cinco capítulos, todos eles subdivididos em vários subcapítulos alguns com sugestivos títulos: "Num dia frio de janeiro", "Pensar a exposição com todo rigor e ambição. Cimentar a confiança”, “A crónica política. Textos de escárnio e maldizer", "Finalmente o catálogo".

O primeiro capítulo, intitulado «Londres, 1881. Conhecer as Artes Ornamentais Peninsulares: Objetivos de uma Exposição» (pp. 15-62), revela-nos uma meticulosa e aturada investigação levada a cabo para iluminar o nascimento da ideia da exposição londrina de 1881 e o labor dos principais atores ingleses e portugueses para concretizar tal desiderato, acrescentando aos últimos também a aspiração simultânea de concretizar o museu nacional.

4 Tendo como ponto de partida «Os antecedentes britânicos» da exposição, para além da informação sobre o lugar histórico do conceito de loan collection (que o marquês de 
Sousa Holstein em 1868 referia como «aquellas collecções de objectos emprestados [...] que sem esta circunstancia nunca poderiam ser vistos») ${ }^{1}$ e o desejo do South Kensington Museum de recolher há anos todos os bens possíveis ou, como se escreveu em 1881, journeys of exploration in the Peninsula (Robinson 1881, 9), postura que Fialho de Almeida criticaria duramente na publicação 0 s Gatos $^{2}$, fica também claro nesta parte do livro o papel charneira do conservador do South Kensington Museum, John Charles Robinson, e a importância das suas "prestigiadas ligações internacionais" (p. 19) bem patentes quando este deu à estampa em julho de 1869 uma carta de candidatura para o lugar de Slade Professor of Art na Universidade de Oxford. ${ }^{3}$

O segundo capítulo mostra-nos, como o título sugere, «A Península Ibérica em Londres. Bastidores e Imagem de uma Exposição» (pp. 63-111) elucidando como se concretizou a exposição londrina não sem que antes a autora tenha dedicado algumas páginas à história do próprio South Kensington Museum aflorando, entre outros tópicos, a sua abertura em 1856, a ação de Henry Cole, a política de exposições itinerantes - o travelling museum tão admirado por Ramalho Ortigão, Fialho de Almeida e Joaquim de Vasconcelos -, a renovação das instalações, e regressando, last but not least, ao papel de John Charles Robinson que qualifica acertadamente como o "mentor, comissário e estudioso" (p. 69) da exposição de arte ornamental ibérica.

Nesta envolvente caminhada, destaque ainda para a análise aturada da imprensa de então. Primeiro, face à abertura da Special Loan Exhibition of Spanish and Portuguese Ornamental Arts em 11 de junho de 1881. Depois, procurando, quer na imprensa portuguesa quer na britânica, o impacto da exposição londrina, ora citando o Diário de Notícias, o Commercio do Porto, mas logo o Times, o Daily Telegraph ou a Pall Mall Gazette, relevando o papel destes três últimos periódicos suprindo a falta de catálogo durante o tempo em que decorreu a exposição. Sob o subtítulo «O fim da Exposição e o seu Saldo» (pp. 108-111) Emília Ferreira conclui que a experiência de Londres foi muito proveitosa não só para a divulgação dos nossos tesouros artísticos, mas ainda "para a urdidura do sonho do museu nacional" (p. 110).

No capítulo terceiro da obra - «A Preparação da Exposição de Lisboa. Portugal em vias de se Apresentar "Desassombradamente Perante a Europa"» (pp. 113-162) - a autora começa por recordar que no mesmo dia em que a exposição se inaugurou na capital londrina, surgia na imprensa portuguesa o "primeiro sinal público" (p. 115) da sua possível reedição em Lisboa. De seguida transporta o leitor para dentro do universo da futura exposição na capital portuguesa, fazendo-o ao partilhar o elenco dos principais comissários - cujos rostos 0 Occidente retrataria em 11 de julho de 1882 em gravura de Alberto -, as decisões, as críticas, as obras no palácio Alvor e, por fim, relevando o rigor científico e museográfico da organização da exposição.

8 De entre a matéria interessante carreada pela autora deve destacar-se a que dá conta das "preocupações documentais" (p. 151) da comissão, "quer com a realização de um catálogo, quer com o registo fotográfico" (p. 151). Para esta segunda novel tarefa, na impossibilidade de contratar em Madrid a J. Laurent \& Cía, a comissão solicita os bons ofícios do fotógrafo amador português Carlos Relvas. Cremos que carece de alguma clarificação esta opção por J. Laurent, o fotógrafo francês - na verdade manteve sempre a sua nacionalidade de origem - que se encontrava sediado em Madrid e Paris como se via estampado no seu carro-laboratório retratado numa chapa de colódio-húmido de 1872. Ao endereçar o convite a J. Laurent, Delfim Guedes era certamente conhecedor do trabalho feito por aquele em março de 1869 para a Academia de Belas Artes de Lisboa a 
pedido do seu antecessor no cargo de vice-inspetor, o marquês de Sousa Holstein (Araújo 2010).

9 O quarto capítulo - «Sobe o Pano. Lisboa em Festa» (pp. 163-250) - bastante mais longo que os outros, é, todo ele, o culminar de um árduo mas frutífero percurso, uma investigação que recorre exemplarmente a uma vasta leitura da imprensa da época que balançou entre elogios e críticas. Esses textos falam sobretudo da instalação, dos critérios de recolha e exposição, além da política de entradas na exposição, querela que tocou os membros da imprensa, mas também os estudantes e as classes laboriosas.

Para o título «Ecos na Imprensa» (pp. 165 e ss.) Emília Ferreira recorreu a periódicos como La Ilustración Española, O Occidente e O António Maria, entre outros, publicando algumas imagens ao correr do texto que, na verdade, ajudam na fluência do mesmo. Pena é que as ilustrações e o texto de Rafael Bordalo Pinheiro estampados no número de 2 de março de 1882 d' $O$ António Maria, número consagrado à exposição, tenham ficado de fora.

11 No quinto e último capítulo da obra - «Antes de Fechar as Portas» (pp. 251-273) -, o mais curto de todos, a autora "relata" as derradeiras ações da comissão e dá conta do(s) balanço(s), incluindo as contas, salientando o seu rigor. No subcapítulo «Preparar a Memória» é retomada a meritória intervenção de Carlos Relvas. O convite, já o sabemos, foi feito em 25 de agosto de 1881 ao abastado proprietário agrícola ribatejano, possuidor do mais belo estúdio fotográfico existente entre nós (1876) e já então membro da prestigiada Société Française de Photographie, na verdade era-o desde 1869. ${ }^{4}$ Relvas, já depois de encerrada a exposição dará à estampa com clichés da sua autoria a conhecida publicação intitulada Exposição Retrospectiva de Arte Ornamental em Lisboa. 1882. Álbum de Phototypias de que se conhecem não duas (como refere o filho de Relvas no prefácio citado por Emília Ferreira na p. 263: «Vem a propósito referir-me á collecção de photographias, feita por meu pae [...] D'esta collecção photographica sahiram apenas duas series de reproducções, uma superior a cem provas, todas de objectos differentes, e outra de duzentos e duas provas [...]», mas sim quatro versões segundo António Sena ${ }^{5}$.

12 Na «Conclusão» (pp. 275-280) fica claro que à partida a participação lusa na exposição de Londres no South Kensington Museum poderia parecer condenada a uma existência, digamos, efémera. Mas cedo se formara entre os comissários, garante a autora, a "ideia da mostra de Lisboa" (p. 276). 0 desejo de um museu nacional sediado na capital vinha, também, peregrinando desde há anos entre a intelectualidade lusa. Por tudo isto, a $\mathrm{A}$ Exposição Retrospetiva de Arte Ornamental Portuguesa e Espanhola, com abertura em Lisboa 200 curtos dias após a inauguração da exposição londrina, foi marcada por um intenso e diversificado trabalho dos membros da comissão. Para a autora - como escreve nas derradeiras linhas do seu trabalho - a exposição do Palácio Alvor foi «não um dos mais notáveis acontecimentos culturais do Portugal oitocentista [...] Mas, e até prova em contrário [...] o mais notável de todos» (p. 280).

13 O trabalho em apreço institui-se como uma obra de referência no âmbito dos estudos de museus, área em que Emília Ferreira, investigadora do Instituto de História da Arte da Faculdade de Ciências Sociais e Humanas da Universidade Nova de Lisboa, se tem revelado uma especialista. Recorde-se, a propósito, a sua dissertação de mestrado intitulada História dos Museus Públicos de Arte no Portugal de Oitocentos: 1833-1884, de 2001, e o capítulo «Building up from the London 1881 Pretext: The Birth of the Portuguese National 
Fine Art Museum» (Ferreira 2014) incluído na obra The Museum is Open: Towards a Transnational History of Museums 1750-1940.

\section{BIBLIOGRAFIA}

Almeida, Fialho de. 1889. Os Gatos. Publicação Mensal d'Inquerito á Vida Portugueza. Porto: Casa Editora Alcino Aranha \& Ca , n. ${ }^{\circ}$, agosto, p. 52.

Araújo, Nuno. 2010. “A Singular Viagem do Fotógrafo Jean Laurent a Portugal, em 1869.” CEM, Cultura, Espaço e Memória: Revista do CITCEM 1: 87-108. http://hdl.handle.net/10216/56033

Ferreira, Emília. 2001. "História dos Museus Públicos de Arte no Portugal de Oitocentos: 1833-1884." Dissertação de mestrado em História da Arte, Universidade Nova de Lisboa.

Ferreira, Emília. 2014. "Building up From the London 1881 Pretext: The Birth of the Portuguese National Fine Art Museum." In The Museum is Open: Towards a Transnational History of Museums 1750-1940, editado por Andrea Mayer e Bénédicte Savoy, 221-232. Berlin: De Gruyter.

Holstein, Marquês de Sousa. 1868. "Prefácio." In A Antiga Escola Portuguesa de Pintura. Estudo sobre os Quadros Atribuídos a Grão Vasco por J. C. Robinson. Lisboa: Sociedade Promotora das Bellas Artes.

Letter of Application of J. C. Robinson for the Office of Slade Professor of Art in the University of Oxford, and Testimonials in his Favour. 1869. London: Whittingham and Wilkins, at the Chiswick Press.

Robinson, John Charles. 1881. "Introduction." In Catalogue of the Special Loan Exhibition of Spanish and Portuguese Ornamental Art, South Kensington Museum, edited by John Charles Robinson, p. 9. London: Chapman \& Hall.

Sena, António. 1991. Uma História de Fotografia. Portugal 1839 a 1991. Lisboa: Imprensa Nacional-Casa da Moeda.

\section{NOTAS}

1. Prefácio do marquês de Sousa Holstein à obra A Antiga Escola Portuguesa de Pintura. Estudo sobre os Quadros Atribuídos a Grão Vasco por J. C. Robinson $(1868,23)$. O texto de John Charles Robinson nasceu de uma viagem a Portugal realizada em outubro de 1865 e foi publicado originalmente em The Fine Arts Quarterly Review existindo em separata em língua inglesa: «The Early Portuguese School of Painting, with notes on the pictures at Viseu and Coimbra traditionally ascribed to Gran Vasco» (London, 1866).

2. «Há setenta anos [sic] que o South-Kensington-Museum, de Londres, secretamente mantém entre nós agentes seus, com ordem de vindimarem o paiz de todos os objectos d'arte que apareçam» (Almeida 1889, 52).

3. Letter of Application of J. C. Robinson for the office of Slade Professor of Art in the University of Oxford, and Testimonials in his Favour (1869). Dele disse Dom Fernando II nesse texto: «I have always found Mr. Robinson possessed of the highest Art knowledge, and I fully agree with him in his account of our early Portuguese Painters, in his interesting pamphlet on the subject". Idem, p. 9. 
4. Não será de estranhar que tenhamos encontrado numa listagem das ofertas à Société Française de Photographie para o ano de 1886 elaborada por Paul Marillier a seguinte nota: «M. Relvas (Carlos) adresse à la Société un exemplaire du magnifique album dans lequel il a consacré le souvenir de l'Exposition retrospective de l'art ornemental qui a eu lieu à Lisbonne en 1882» (in http:// www.sfp.asso.fr/collection/index.php/recherche-dans-la-collection/dons-recus-par-la-sfpde-1855-a-1971).

5. «Uma, encadernada, com 55 fototipias impressas por J. Leipold [...], outra em duas pastas contendo 123 e 202 fototipias, e outra (única ao que suponho) com mais de 500 assinadas pelo autor» (Sena 1991, 29).

\section{AUTORES}

\section{PAULO OLIVEIRA RAMOS}

Universidade Aberta e Instituto de História da Arte (IHA) da Faculdade de Ciências Sociais e Humanas da Universidade Nova de Lisboa, Portugal, paulooliveiraramos@gmail.com 